The rescued emotion: ethics and aesthetics through Wittgenstein

\title{
La emoción salvada: ética y estética a través de Wittgenstein
}

Rosa Gutiérrez García

Universidad Complutense de Madrid rosagu01@ucm.es

DOI: https://doi.org/10.15366/bp.2020.24.019

Bajo Palabra. II Época. No 24. Pgs: 385-400

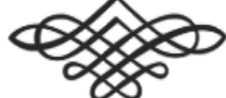


Recibido: 27/01/2020

Aprobado: 12/08/2020

\section{Resumen}

El presente artículo estudia la noción del silencio en la ética y en el arte, investigando las correlaciones entre lo bello y lo bueno a partir del misterioso aforismo de Wittgenstein: "Ética y Éstética son Uno".

Palabras clave: Ética, Estética, Wittgenstein, Silencio, Misterio, Secreto, Simbolo.

\section{Abstract}

This article studies the notion of silence in ethics and art, considering the relationship between beauty and the ethical from Wittgenstein's mysterious aphorism: "Ethics and Aesthetics are One". 
En todo gran arte hay una bestia salvaje domada. ${ }^{1}$

WiTTGENSTEIN

\section{Mutismo en la Viena fin de siècle}

En igoi, el poeta austriaco Hugo von Hofmannsthal, quien más musicalidad había otorgado a la lengua alemana en los dos últimos siglos, de repente deja de escribir poesía. Bajo la forma de una ficción literaria y usando el pseudónimo de Lord Chandos, escribe una carta dirigida a Francis Bacon con el objetivo de comunicarle una experiencia insólita: la incapacidad de encontrar en el lenguaje ningún elemento con el que poder expresarse:

Quería descifrar las fábulas y los relatos míticos que los antiguos nos legaron, esos en los que pintores y escultores, ingenuamente, se deleitan hasta el infinito: jeroglíficos de una sabiduría secreta, inagotable, cuyo hálito creía sentir en ocasiones, como desde detrás un velo. ${ }^{2}$

Este testimonio de quiebra de la palabra ilustra el melancólico horizonte de la Viena finisecular, concebida como un gran "experimento mental" (Gedankenexperiment) cuyos valores, que antaño habían ordenado la vida del hombre, ahora se revelaban insuficientes, confusos, desordenados, indescriptibles mediante la palabra: "nada se dejaba ya delimitar por un concepto". ${ }^{3}$ La Viena de finales del siglo XIX, con el Imperio austro-húngaro en paulatina decadencia como potencia internacional, el auge de los nacionalismos y un progresivo declive económico, se conjugó con el surgimiento de una pléyade de artistas, con motivo del asentamiento de la burguesía y el consecuente fracaso del liberalismo, que produjo un auge cultural prácticamente incomparable.

\footnotetext{
1 Wittgenstein, L., (2009). “Observaciones diversas. Cultura y valor”, en Wittgenstein II. Diarios. Conferencias. Madrid: Gredos, p. 600.

2 Hofmannsthal, H., (2012). Carta de lord chandos (Centellas). Palma de Mallorca: José J. de Olańeta, p. 24.

3 Hofmannsthal, H., (2012). Op. Cit, p. 32
} 
En esta paradójica escena, el mutismo se debía, para Hofmannsthal, a la incapacidad de los clásicos para unir al hombre fragmentado -que ahora debía hacer un largo e intrincado rodeo intelectual para reestablecer la unidad perdida entre el sujeto y el objeto- y también de la ciencia, para abarcar un todo escindido: "sentimos que aun cuando todas las posibles cuestiones científicas hayan recibido respuesta, nuestros problemas vitales todavía no se han rozado en lo más mínimo". ${ }^{4} \mathrm{El}$ matemático idealista Ulrich, al que la imaginación de Musil dio vida, es el perfecto ejemplo de hombre que vive en un mundo de posibilidades y no de realidades.

[Ulrich] Medía las velocidades, los ángulos, las fuerzas magnéticas de las masas fugitivas que atraen hacía sí al ojo fulminantemente, lo sujetan, lo sueltan [...]. En resumen, después de haber hecho cuentas mentalmente unos instantes, metió el reloj en el bolsillo, riendo y reconoció haberse ocupado en una estupidez. ${ }^{5}$

En efecto, El hombre sin atributos es aquel que vive más cerca de las posibilidades que de los hechos, y no deja de ser paradójico que éste personaje sea precisamente un matemático, que en todo caso se rige por la ley científica. Tampoco Wittgenstein consideraba que las ciencias fueran capaces de transmitir ninguna unidad, y en esta idea se percibe la creencia, la necesidad ética, de que el mundo material hallase un correlato en el mundo espiritual.

Todo este complejo entramado de silencio tenía un denominador común: el rechazo a la cháchara tan común en la época, en la que en ocasiones el silencio suponía además un precepto de orden ético: "iquien tenga algo que decir, que se adelante y calle". ${ }^{6} \mathrm{La}$ fascinación por el orador, que tanto había contribuido al auge del nacionalsocialismo, se cifraba, como no podía ser de otro modo, en el desprecio al silencio: "un hombre que advierte un posible peligro tiene el deber, no de trabajar en silencio, sino de erguirse públicamente ante el mal". ${ }^{7}$ El silencio, en efecto, se constituía como la única acción ética posible ante la manipulación política del lenguaje, ${ }^{8}$ acción ética que Karl Kraus ejemplificó suspendiendo su satírica publicación Die Fackel.

Wittgenstein, por su parte, plantea una disyuntiva en el Tractatus: claridad o silencio. Su fundamento se hallaba en el isomorfismo del lenguaje y del mundo, postulando que "lo que cualquier figura, sea cual fuere su forma, ha de tener en

\footnotetext{
4 Wittgenstein, L., (2016). Tractatus Logico-Philosophicus (en adelante TLP), Madrid: Alianza, 6.52.

5 Musil, R., (2001). El hombre sin atributos, vol. I, Barcelona: Seix Barral, p. 14.

${ }^{6}$ Kraus, K., (1977). La tercera noche de Walpurgis. Barcelona: Icaria, p. 12.

7 Hitler, A., (1990). Mi lucha. Barcelona: Torradas.

${ }^{8}$ Kovacsics, A. (2007). Guerra y lenguaje (1a. ed., El acantilado). Barcelona: Acantilado, passim.
} 
común con la realidad para poder siquiera -correcta o falsamente- figurarla, es

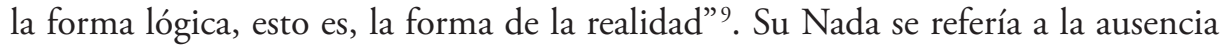
absoluta, a lo inexistente, no a la negación de algo. Lo que nos interesa ahora de este pensamiento es la intención de poner contra las cuerdas el sistema propio de la lógica, asumiendo que lo que se encuentra fuera del lenguaje no puede estar dentro del mundo. En este sentido, lo absoluto habitaría el espacio de lo indecible; al fin y al cabo, "no afirmaríamos que nuestro saber es fragmentario si no tuviéramos la noción de un todo". ${ }^{10}$ El lenguaje tiene un límite que señala lo indecible.

\section{Lo indecible, lo absoluto y lo místico: Nosce te ipsum}

El CONCEPTO DE LO Místico en el Tractatus se refería a lo inefable de la existencia del mundo en su totalidad, no al modo en que el mundo se presenta -de facto, en los hechos-y por tanto, no al qué-es sino al que-es del mundo; a que el mundo sea, en definitiva: "no cómo sea el mundo es lo místico sino que sea". ${ }^{11}$

Con Wittgenstein, lo absoluto es una flecha que apunta hacia lo indecible. Por tanto, si la función del lenguaje era la de describir el mundo, este solo podría verificar aquél en correlato con un valor absoluto, y este valor permanecería, en última instancia, incognoscible: "el sentido del mundo debe quedar fuera del mundo". ${ }^{12} \mathrm{En}$ realidad, la preocupación fundamental de la época residía en dilema "yo-mundo", o si se quiere, su dramática separación. En Lord Chandos la ausencia de una visión coherente que explique la propia existencia se da, como en Wittgenstein, también en términos existenciarios. Lo que ambos ya no pueden hacer es responder a esa esfinge tan humana que interrogara cruelmente a Edipo. El ser humano tiene que responder de sí mismo, pero uno no responde sino con palabras, "siempre en vecindad con la palabra", ${ }^{13}$ y ante la imposibilidad ya declarada del lenguaje de decir la verdad del valor, uno se pregunta, ya no qué decir tanto como “iqué ser?" Parece que el problema metafísico de Wittgenstein se planteaba también en términos de pura existencia, pero una existencia trágica que no era capaz de encontrar vías para ser definida.

Aquí, lo metafísico deviene, inevitablemente, lo místico. Ahora bien, no porque los valores no existan en el mundo, en términos kantianos, es decir, como trascendentales, sino porque eso trascendental no puede existir como discurso; no puede,

\footnotetext{
9 Wittgenstein, L., (2016). Op cit, 2.18

${ }^{10}$ Goethe, W., (1968). "Esbozo de una teoría de los colores”, en Obras Completas, vol. III, Madrid: Aguilar, $\$ 1154$.

11 Wittgenstein, L., (2016). Op cit, 6.44.

12 Wittgenstein, L., (2016). Op cit, 6.41.

13 Madrigal, P., (1978). Rober Musil y la crisis del arte. Madrid: Tecnos, p. 100.
} 
en definitiva, conocerse. Los valores, dirá Wittgenstein, no pertenecen al mundo de los hechos, único mundo en que se posibilita al ser humano a decir algo: "Hay, en verdad, lo inexpresable. Ello se muestra; es lo místico". ${ }^{14}$ Lo místico hace referencia


rrar, estar cerrado). La mística se encuentra cerrada sobre sí misma. Es silencio, pero silencio proclamado como tal. Lo místico siempre traduce una experiencia inefable, intransmisible, que se encuentra en las afueras de cualquier lógica; puede ser, por tanto, explicado parcialmente, pero su sentido permanece herméticamente cerrado: no puede ser transferido lo que solo tiene un adentro. La ética, para Wittgenstein, no está conformada por proposiciones (enunciados) de hecho, y lo que no pertenece al mundo de los hechos no resulta expresable. La ética, en tanto que trascendental, no es comunicable, y todo trascendental absoluto -es decir, todo valor- no puede representarse por el lenguaje.

Veo ahora que estas expresiones carentes de sentido no carecían de sentido por no haber hallado aún las expresiones correctas, sino que era su falta de sentido lo que constituía su mismísima esencia. Porque lo único que yo pretendía con ellas era, precisa mente, ir más allá del mundo, lo cual es lo mismo que ir más allá del lenguaje significativo. ${ }^{15}$

Lord Chandos quería escribir un libro enciclopédico interpelado por el aforismo de Juvenal, un encargo ético que el hombre está llamado a hacerse: el encargo de conocerse a uno mismo. Dar cuentas, en definitiva, ante la esfinge que tutela las puertas de la ciudad de Tebas - de toda ciudad en la que el hombre vive con otrossugiriendo, tal vez, que quien se desconoce no puede habitar un espacio, quedando condenado, en definitiva, al exilio. Era esta imposibilidad de decirse a uno mismo, de narrarse -de conformarse la existencia- la verdadera tragedia que encerraba el silencio en la Viena finisecular.

\section{Geheimnis en lo ético y en lo estético "Ethik und Aesthetik sind Eins" 16}

EXIsTe Lo místico, entonces, para Wittgenstein, pero su incomunicabilidad lingüística hace de éste que cognoscitivamente no sirva al hombre de ninguna ayuda.

\footnotetext{
14 Wittgenstein, L., (2016). Op cit, 6.522.

15 Wittgenstein, L., Conferencia sobre ética. Edición Electrónica de www.philosophia.cl / Escuela de Filosofía Universidad ARCIS. Con "Notas de las conversaciones con Wittgenstein" de Friedrich Waismann y "Acerca de la concepción wittgensteiniana de la ética" de Rush Rhees, p.8. Esta conferencia fue publicada por primera vez en "The Philosophical Review", vol. LXXIV, n. 1, en enero de 1965.

16 Wittgenstein, L., (2016). Op cit, 64.21.
} 
Lo místico se resuelve, por ello, como la única manera ética de vivir: mysticum modus vivendi unicus est. Es la máxima wittgensteniana, su imperativo categórico.

De esta manera, expone su famosa proclama en el Tractatus: "Ethik und Aesthetik sind Eins". A modo de corolario, y entre paréntesis, parecía que el autor tenía la intención de desarrollar este aforismo sorprendente de forma más pausada y conveniente, quizá en otra obra, quizá en otro momento, pero finalmente no se llegó a ocupar de ello en su justa medida. "Ética y estética son UNO" ("sind eins"). En un primer acercamiento, la frase parece tener la voluntad sutil de distinguirse de otra posible sentencia: ética y estética son lo mismo. Es decir: lo mismo y lo uno. Lo que se parece y lo que es lo mismo.

El autor escribe este aforismo en el mismo contexto en que afirma que el valor de la ética es trascendental, y por ello un absoluto incognoscible e incomunicable como tal. La trascendentalidad de la ética y de la estética se enuncia en la lógica, remitiendo de nuevo a un sujeto limitado, incapaz de nombrar lo inexpresable de un valor cuyo centro está cerrado en sí mismo. Wittgenstein alude a la unidad de la ética y de la estética porque vincula ambas como forma de vida, esto es, lo esencial para el ser humano, pero de lo que éste no puede decir nada. En este sentido, Wittgenstein no asocia, como se venía haciendo desde Baumgarten, estética y belleza; tampoco estética y arte, porque para el autor el arte es una práctica -un hecho- y la estética cumple un papel de acto de habla, por lo que es el lenguaje el que dice algo de la práctica del arte. Para este lenguaje no es relevante su significado -que no lo tiene como tal- sino lo que siente el espectador como reacción espontánea, casi como un reflejo proveniente de la contemplación de la obra. De la obra de arte podemos decir, en opinión de Wittgenstein, algo de ella como reacción: "El capullo que se abre. ¿¿ué es lo hermoso en ello? Se dice: “iver cómo se abre!”. ${ }^{17}$

\section{Secreto y símbolo}

GEHEIMNIS EN LENGUA ALEMANA contempla dos significados simultáneos: "secreto" y "misterio". Goethe las distingue, en su Teoría de los colores, para señalar que el secreto se agota con el descubrimiento de su causa, pero el misterio -"secreto manifiesto"- es el que se presenta delante del sujeto, y en ese potencial descubrimiento, es decir, en ese ofrecimiento de desvelamiento reside la capacidad mistérica del objeto, incluso cuando éste ya ha sido desvelado. Lo que se colige rápidamente de

\footnotetext{
${ }_{17}$ Wittgenstein, L., (1996). Lecciones y conversaciones sobre estética, psicología y creencia religiosa, ed., (Pensamiento contemporáneo). Barcelona: Paidós, p.103.
} 
Goethe es una percepción inmediata del sentido y en ocasiones una renuncia a la búsqueda de lo causal, que se muestra como tal, en tanto que presencia. El fenómeno originario (Urphänomen), con que describe, por ejemplo, la metamorfosis de las plantas, es entendido por el pensador alemán como símbolo, y por tanto como algo indecible, porque "no vehicula un contenido conceptual, sino que deja transparentar algo que está más allá de toda expresión". ${ }^{18}$

En este sentido, la naturaleza, como columna vertebral de lo suprasensible, tiende un puente al entendimiento, que le sirve de enlace con lo fenoménico, que la naturaleza cifra como un secreto. Sin embargo, en opinión de Kant, (KU) es este un conocimiento que siempre constituirá un límite de sí mismo, pues su forma de conocerlo procede mediante símbolos. En Wittgenstein -lo estamos viendo- se desprende la creencia de que si el lenguaje pudiera figurar la realidad (y para Wittgenstein no puede) ello sería factible porque lenguaje y realidad compartirían la misma estructura o forma lógica. Entonces, la forma lógica mediaría, inevitablemente, entre el lenguaje que permite enunciar proposiciones subjetivas ("la totalidad de proposiciones es el lenguaje") ${ }^{19}$ y el mundo de los hechos como realidad objetiva. Ello ocurre porque Wittgenstein piensa la "figura" (Bild) como universal; la proposición o enunciación de un hecho mediante el lenguaje supondría un retrato de forma lógica de un hecho, de una figura de la realidad.

Lo que cualquier figura, de cualquier forma, debe tener en común con la realidad para poderla representar de algún modo es la forma lógica, es decir, la forma de la realidad. ${ }^{20}$

Entonces, Bild deviene entidad sustituta respecto a lo figurado por ella misma. La figura es un modelo de la realidad, no su representación; una figura que además Wittgenstein reconoce como simbólica, cuya expresión permite una manifestación en el mundo donde lo ético-estético resuena: "Esa expresión simbólica a la que ya nos hemos referido tiene la peculiaridad de permitir una mostración, en el objeto, o en ciertos episodios del mundo". ${ }^{21}$ No deja de ser sintomático que en alemán, Sinnbild (imagen sensible) se traduzca por símbolo. Lo simbólico ( $\sigma u ̛ ́ \mu \beta o \lambda o v, ~ s y m-$ bolon), que deriva del verbo $\sigma u \mu$ (juntar) $\beta \alpha ́ d \lambda \lambda \varepsilon v v$ (lanzar), en su significado etimológico deviene relevante: lanzar conjuntamente; $y$, al lanzar, volver a unir. El símbolo, literalmente, es aquello que reúne lo que estaba incompleto: la revelación

\footnotetext{
${ }_{18}$ Hadot, P., (2015). El velo de Isis: ensayo sobre la historia de la idea de naturaleza. Barcelona: Alpha Decay, pp. 29-31.

19 Wittgenstein, L., (2016). Op cit, 4.001

${ }^{20}$ Wittgenstein, L., (2016). Op cit, 2.18.

21 Trías, E., (2001). "Ética y estética”, (Novenas Conferencias Aranguren), en Isegoría, no 25, p. 172.
} 
no es otra cosa que la reunión de dos partes que generan un nuevo sentido. A juicio de Eugenio Trías, la revelación se produce en primera instancia en el mundo de la naturaleza, y en segunda instancia en el ámbito simbólico. "El acontecimiento sym-bálico da forma al ser del límite." 22 Lo interesante de esta reflexión es que ese yo revelador es un ser en el límite, en el límite mismo del conocimiento y de su propio ser.

\section{Lo inexpresable y lo inexistente: el error ontológico}

Por tanto, si el absoluto se revela inaccesible, y esto inaccesible es lo místico cuyo significado se vacía en sí mismo, y las proposiciones del lenguaje son figuras - modelos compuestos de la realidad, incognoscibles, pero no por ello inexistentes- se colige de Wittgenstein la imposibilidad de representar la belleza, pues ésta responde a un orden esencial. Cabe representar, acaso, algo bello, de lo que tampoco sabríamos decir qué es exactamente.

Sin embargo, cuando algunas emociones de placer o sufrimiento alcanzan su cuota más alta, decimos que la expresión de los mismos se torna indescriptible. Así, la confusión entre lo inefable y lo irrepresentable asentó la creencia en un arte místico, que procuraba más placer cuantos más secretos impenetrables contuviese. ${ }^{23}$ Pero el comienzo de la comprensión de la belleza se da como hecho y no como esencia. Su requisito se da como racionalidad, como factum - es decir, la obra de arte en su estar ahí-. Si lo inefable fuera irrepresentable, como sostiene Wittgenstein, y también inteorizable, por su condición de indecible, la representación de la belleza devendría imposible en el arte figurativo, lo que equivaldría a imponer una mordaza al arte, pues la belleza como valor pertenece al orden de las esencias. $\mathrm{Ni}$ que decir tiene que por esta misma teoría, la absoluta abstracción en un lienzo en blanco (Fontana), azul (Klein) o negro (Reinhardt) representaría la idea de belleza como potencialidad sin ser por sí mismos, bellos. No nos cuesta imaginar la metafísica negativa que este pensamiento sigue produciendo en el arte desde la Segunda Guerra Mundial hasta nuestros tiempos, proveniente de la confusión entre lo indescriptible y lo irrepresentable.

Lo que permanece inexpresado [en la obra de arte], siendo no obstante de naturaleza expresable, lo puede intuir el espectador completando la expresión de la obra, puesto que

\footnotetext{
22 Trías, E., (1994). La edad del espíritu. Barcelona: Destino, p. 347.

23 Gutiérrez, R., (2019). "La Teoría del velo", en Fedro, Revista de Estética y Teoría de las Artes, no 19, pp. 182211.
} 
pertenece por derecho propio a la significación objetiva de la pieza expresiva. La trascendencia de esta función complementaria de la contemplación anula la teoría de la incomunicabilidad de la esencia de la obra de arte. ${ }^{24}$

Si este antiarte al menos fuera sincero, ni Duchamp ni Malevich, ni otros artífices del abstracto, de lo antifigurativo y del experimento, influidos como estaban por las teorías wittgenstenianas hubieran bautizado con ningún nombre a sus obras, porque expresando lo que la ley objetiva de la expresión no muestra per se, el nombre se incorpora como algo dado artificialmente, a posteriori. Lo que hizo Duchamp fue romper con la estética para evidenciar la consagración de la falta de ética en el arte de su siglo. La fealdad de la obra duchampiana nos indica la relación ética-estética más que nunca. Esa ruptura fue la auténtica novedad -el acontecimiento- y no sus ready-made. El error ontológico que subyace en esta concepción negativa de lo inefable reside todavía en confundirlo con lo inexistente:

La inefabilidad no es condición de la Nada sino de lo inconmensurable o imponderable. Lo indecible en el lenguaje ordinario o filosófico es expresable por el arte. Ésa es la virtud que lo justifica. ${ }^{25}$

Ante la negativa de asumir que el arte tiene un conocimiento racional y posible y que muestra una realidad aprehensible, pareciera que la relación de compromiso entre el sujeto y el objeto desplazase el sentido que aquél ha alumbrado en éste. Ciertamente, el arte tiene que ver con el aparecer, y algo que se aparece es necesariamente algo que no se había aparecido antes. Y todavía podríamos decir: "es una aparición que significa algo" (Sheinen). ${ }^{26}$ Los sentimientos y emociones en grado prominente poseen la condición de inefables, como las ideas de orden esencial. Cuando Isidoro Reguera dijo que "Dios es el lujo conceptual del arte" y que por ello era también "el culmen de la mística" decía lo mismo, en el prólogo de A. A. Puelles, que éste cuando se refería a la belleza como lo místico porque su conocimiento no pertenecía al orden empírico. Su teoría, vemos, es sobre Wittgenstein:

El juego estético de Wittgenstein con lo inefable es místico. No es teórico porque de lo inefable no puede haber teorías [...]. ¿Por qué no hay teoría del arte? Porque el arte mos-

\footnotetext{
${ }^{24}$ Trevijano, A. (2007). Ateísmo estético, arte del siglo XX: De la modernidad al modernismo. México: Landucci, p. 127.

25 Trevijano, A. (2007). Op cit, p. 126.

26 Hegel, F., (1989). Lecciones sobre estética. Madrid: Akal, p. 19.
} 
traría lo místico, sin nombrarlo, sin hablar de ello; o, mejor, porque lo místico se mostraría sin nombre o sin lenguaje lógico en él. ¿Y qué es lo místico? Ah, lo indecible. Algo oscuro, objeto nada más que de sentimientos o intuiciones, a lo cual pertenece, junto con lo estético, lo ético o lo religioso. ${ }^{27}$

Pero lo estético, lo ético y lo religioso se expresaban con lenguajes diferentes. Es cierto que la dificultad teórica de Wittgenstein no se supera equiparando la intuición a la expresión, como hizo Croce en su Aesthetica in nuce, que está en la línea del pensamiento de Bergson, considerando la expresión estética como la traición de las formas a las intuiciones. Croce concebía la intuición como una forma pura del conocimiento, de distinto grado al intelecto que produce conceptos, asemejándolo con la expresión, distinguiéndola de la percepción y sistematizando de un modo nuevo y original su filosofía del espíritu. Al artista, dice, no le mueve la veracidad filosófica de lo representado -como pretendió el cubismo o el arte conceptual- porque ello constituiría una afirmación de realidad (el espíritu), es decir, "un sujeto sin predicados". ${ }^{28}$ Pero la expresión, ciertamente sí vehicula el conocimiento intuitivo, pero ésta conforma "la única ley objetiva [...] que se define por sí misma como síntesis de forma, materia y tema” ${ }^{29}$ Cada lenguaje expresa, de modo diferente -con distintos códigos- el conocimiento de la disciplina que entraña.

La teología no es conocimiento de Dios, algo inefable, indefinible e indescriptible, sino un saber decir de la divinidad en el discurso de la lengua o en la vivencia de la emoción mística. La estética tampoco es el conocimiento de la belleza, una idea universal tan inefable como la de Dios, sino un saber decir de lo bello inscrito en el libro de la naturaleza o en la vivencia de la emoción artística. Nada se asemeja tanto a la esencia de la divinidad, manifestada en la creación de lo bello por naturaleza, como la esencia de la belleza expresada en las creaciones del arte genial. ${ }^{30}$

Entonces, belleza, bien y Dios (estética-ética-religión) dejan de ser inefables cuando son representados como valores, cuando devienen representación de valores, y se posibilitan como tales cuando no se extraen de un horizonte trascendental.

\footnotetext{
27 Puelles, A., \& Reguera, I. (2002). El arte de lo indecible: Wittgenstein y las vanguardias). Cáceres: Universidad de Extremadura, Servicio de Publicaciones, p. 13.

28 Croce, B., (1994). Breviario di estética. Milano: Adelphi Edizioni, $3^{\circ}$ ed, p. 31.

29 Trevijano, A. (2007). Op. Cit, p. 127.

30 Trevijano, A. “Evolución de la estética” en La Razón (2002-2003), 19/08/2002, p. 34.
} 


\section{Escolios}

Parece QUe la Ética fundamenta una estética, si consideramos la estética en el sentido de una la disciplina que trata "la percepción de los valores" ${ }^{31}$, y a la ética como la que estudia el fundamento de tal consideración. Pero la sinceridad que nos importa -donde reside la ética- es la de la propia obra. No es que una obra tenga que decir algo bueno o verdadero de forma necesaria, sino que lo que diga lo exponga de forma verdadera. Y que lo diga la obra, no su autor. La sinceridad ética en el discurso del decir es lo que nos impele a manifestar que la ética fundamenta una estética, pero de ningún modo a considerar, por los motivos ya expuestos, que "Ética y estética son uno".

Cuando Marisallach dijo que "los desnudos hermosos son decentísimos y los feos, inmorales" defendía algo similar a Buenaventura de Bagnorea: "sin embargo, por la misma razón, la imagen del diablo es bella cuando representa bien la fealdad del diablo y por este aspecto es también fea", situando lo moral bajo el prisma de la belleza. ${ }^{32}$ En Sonata a Kreutzer, Tolstoi evidencia su desconfianza por la música, porque al constituir ésta el arte más abstracto, podía inducir al sujeto a estados de ánimo ficticios. Al final de la novela, la mujer del protagonista le abandona por un violinista. En Anna Karenina, la sinceridad que nos importa es la de la obra, independizada del dogma moral que su autor quiso imprimir en ella; a saber, censurar moralmente la relación extramarital de Anna con el conde Vronsky, que acaba conduciendo a todos a una inexorable fatalidad, y ante la que muchos lectores hemos exclamado, sin embargo: “ipero qué bella fatalidad!”. El moralista Tolstoi jamás nos hubiera secundado. La unión de contrarios entre forma y contenido, la pretensión de objetividad a la que se refería Adorno cuando hablaba de Madame Bovary, articulaba con precisión casi científica la narración de una pasión desbordada, casi una patología, dentro de un marco formal, preciso y riguroso, con reglas que pautó el realismo socialista en literatura: "la perfecta educación lingüística en Madame Bovary está probablemente en función del fanatismo contrario". ${ }^{33}$ Muchos ejemplos literarios juzgan lo estético y lo ético y mueven sus ruedas internas, en ocasiones, haciéndonos dudar: Lolita, de Nabokov, o Muerte en Venecia, de Thomas Mann, constituyen altos méritos estéticos que nos trasladan - sin eludir la empatía- a una visión de un mundo éticamente reprobable, de hecho, en ocasiones, a un tabú: la pederastia.

\footnotetext{
31 Santayana, G. (1999). The sense of beauty: Being the outline of aesthetic theory (Trad. Carmen García-Trevijano) Madrid: Tecnos, p. 16

32 "Comentario a las sentencias", (10 ed.) Buenaventura de Bagnorea (siglo XIII) citado por Eco, U., (2011). Historia de la fealdad (1a ed.). Barcelona: Debolsillo.

33 Adorno, T., (1983). Teoría estética (Historia del pensamiento). Barcelona: Orbis, p. 17
} 
Es, desde luego, una cuestión moral la de saber en qué extensión hayan de ser sacrificados los bienes estéticos, puesto que la función de la razón práctica es comparar, combinar y armonizar todos nuestros intereses a fin de alcanzar las máximas satisfacciones de que es capaz nuestra naturaleza. ${ }^{34}$

Hemos de escuchar a Sedlmayr: "el punto de partida para una verdadera historia del arte se encuentra en la obra de arte". ${ }^{35}$ La sinceridad ética que nos importa es la de la obra, no la de su autor; no su tema o su pretexto, ni tampoco su destino. Lo único objetivo es la obra:

No es el artista el que debe inspirar su obra en un propósito moral. Es la obra misma la que, para ser de verdad bella, necesita estar cimentada sobre bases naturales de orden instintivo o prerracional que, quiérase o no, constituyen el fundamento de la moral racional. ${ }^{36}$

Aquí nos estamos preguntando si el modo de pensar estético es el modo de pensar fundamental. La estética, como lo sensible (esthetos: percepción), es claro que supedita a la técnica. La ética depende de una visión estética, pero la visión estética como realidad es por sí misma, inagotable; la historia del pensamiento, de hecho, es justamente la historia de intentar captar las formas sensibles de la realidad, realidad, aquí, en tanto que verdad. Entonces, "los propósitos morales del arte son de orden instintivo". ${ }^{37}$ La estética implica la ética, pero ello no quiere decir -y ésta es una proscripción que obedece a principios éticos- que sea lícito moralizar la belleza. Lo que se colige de ello es que el arte expresa su moralidad por otras vías, acaso "por el uso perfecto de un recurso artístico que ennoblece las imperfecciones de la técnica" ${ }^{38}$ Lo verdadero no es necesariamente bello -la experiencia fácilmente nos habla de verdades crueles- pero por su condición de verdad, y de una verdad que dice algo verdadero, por ejemplo, algo cruel, ¿diríamos de ella que es, por motivo de su crueldad, una verdad fea? Acaso señalaríamos lo feo por el modo de decir una verdad que nos es cruel; apelamos, entonces, a un decoro en el modus dicendi de la verdad, que nos parece más cruel por cómo ésta se emite. El estilo demuestra, siempre y en todo caso, un modo personal de decir algo y el contenido siempre exige un decoro. Una declaración de amor no se hace como propaganda política, ni un discurso político como una manifestación de amor. La ética requiere lo estético,

\footnotetext{
34 Santayana, G., (1969). El sentido de la belleza: esbozo de una teoría estética. Buenos aires: Losada, p. 198.

35 Seldmayr, H., (1958). Kunst und Wahrheit. Hamburg: Rowohlt, p. 116.

36 Trevijano, A. (2007). op cit, p. 122.

37 Trevijano, A. (2007). op cit, p. 122.

38 Trevijano, A. (2007). Ibd.
} 
pero si lo estético se moralizara, perdería su posibilidad ética. De hecho, la mentira fundamenta la creación artística a condición de que la obra sea bella, y por tanto, sincera, y es que "a diferencia del carácter categórico de la sinceridad moral, la artística es siempre relativa" ${ }^{39}$. Ahora bien, ¿̇relativa a qué? A la inteligencia intuitiva del artista, manteniéndose cerca de los fundamentos naturales de la estética, es decir, dando respuesta en sus interpretaciones artísticas a las incesantes demandas de la humanidad. Un comportamiento no estético será feo y además repugnantemente ético. Sin belleza ¿qué queda? ¿un feo moralismo que no vincularía la voluntad?

$\mathrm{El}$ arte debe ser indiscreto. Ha de mentir, como creador de ficciones, pero no disimular la verdad descubierta. Por esa causa, la veracidad artística, graduada con criterios morales inconscientes, está más cerca de la certeza científica que de la seguridad ética. ${ }^{40}$

En todo arte hay una bestia salvaje domada -lo decía Wittgenstein-, pero si el arte vela una pasión domada, esto es, un "animal salvaje" que se refiere al instinto puro creador, la pregunta debe ser ¿qué revela el arte? Contestamos: las emociones salvadas de los abismos. ¿De dónde surge el sentimiento estético? ¿De la comprensión de la belleza como valor absoluto? Decimos: de la capacidad de las pasiones primarias para saberse salvadas en la contemplación efímera de la belleza artística. En este sentido, "lo que expresa el arte es el movimiento contrario del alma" ${ }^{41}$ y "no hay arte que no contenga en sí, en forma de negación, aquello contra lo cual choca" ${ }^{42}$.

\footnotetext{
39 Trevijano, A. (2007). Op cit, p. 124

40 Trevijano, A. (2007). Ibd.

${ }^{41}$ Trevijano, A. (2007). Op cit, p. 38.

42 Adorno, T., (1983). Op cit, p. 23.
} 


\section{REFERENCIAS Bibliográficas}

Hofmannsthal, H., (2012). Carta de Lord Chandos (Centellas). Palma de Mallorca: José J. de Olañeta.

Wittgenstein, L., (2009). "Observaciones diversas. Cultura y valor", en Wittgenstein II. Diarios. Conferencias. Madrid: Gredos

Wittgenstein, L., (2016). Tractatus Logico-Philosophicus. Madrid: Alianza.

Wittgenstein, L., Conferencia sobre ética. Edición Electrónica de www.philosophia.cl / Escuela de Filosofía Universidad ARCIS. Con "Notas de las conversaciones con Wittgenstein" de Friedrich Waismann y "Acerca de la concepción wittgensteiniana de la ética” de Rush Rhees.

Wittgenstein, L., (1996). Lecciones y conversaciones sobre estética, psicología y creencia religiosa, ed., (Pensamiento contemporáneo, 22). Barcelona: Paidós.

Adorno, T., (1983). Teoría estética (Historia del pensamiento). Barcelona: Orbis Buenaventura de Bagnorea (siglo XIII) "Comentario a las sentencias", (1º ed.) recogido por Eco, U., (2011). Historia de la fealdad (1a ed.). Barcelona: Debolsillo.

Croce, B., (1994). Breviario di estética. (30 ed). Milano: Adelphi Edizioni.

Dewey, J., (2008), El arte como experiencia. Barcelona: Paidós (Estética).

Goethe, W., (1968). "Esbozo de una teoría de los colores”, en Obras Completas, vol. III, Madrid: Aguilar. $\$ 1154$

Hadot, P., (2015). El velo de Isis: ensayo sobre la historia de la idea de naturaleza. Barcelona: Alpha Decay D.L.

Hegel, F., (1989). Lecciones sobre estética. Madrid: Akal.

Hitler, A., (1990). Mi lucha. Barcelona: Torradas.

Kraus, K., (1977). La tercera noche de Walpurgis. Barcelona: Icaria.

Kovacsics, A. (2007). Guerra y lenguaje (1º. ed., El acantilado, 158). Barcelona: Acantilado.

Musil, R., (2001). El hombre sin atributos, vol. I, Barcelona: Seix Barral.

Madrigal, P., (1978). Rober Musil y la crisis del arte. Madrid: Tecnos. 
Puelles, A., \& Reguera, I. (2002). El arte de lo indecible: Wittgenstein y las vanguardias). Cáceres: Universidad de Extremadura, Servicio de Publicaciones

Santayana, G. (1999). The sense of beauty: Being the outline of aesthetic theory (Trad. Carmen García-Trevijano) Madrid: Tecnos.

Seldmayr, H., (1958). Kunst und Wahrheit. Hamburg: Rowohlt.

Shakespeare, King Lear, Act I, scene I.

Trevijano, A. (2007). Ateísmo estético, arte del siglo XX: De la modernidad al modernismo. México: Landucci, p. 127.

Trías, E., (1994). La edad del espíritu. Barcelona: Destino.

Trías, E., (2001). "Ética y estética", (Novenas Conferencias Aranguren), en Isegoría, no 25, pp. 147-175.

Valéry, P., (1990). Teoría poética y estética. Madrid: La balsa de la Medusa.

DOI: https://doi.org/10.15366/bp.2020.24.019

Bajo Palabra. II Época. No 24. Pgs: 385-400 